\title{
Perceções dos investigadores face ao ecossistema da Ciência Aberta: estudo preliminar
}

\author{
Percepciones de los investigadoreas sobre el ecosistema de la ciencia abierta: estudio preliminar
}

Researchers' perceptions towards the Open Science ecosystem: a preliminary study

\author{
Maria Luz Antunes (1), Carlos Lopes (2), Maria Manuel Borges (3), Tatiana Sanches (4) \\ (1) ESTeSL (Instituto Politécnico de Lisboa), Portugal, ORCID 0000-0003-0942-7601, mluz.antunes@estesl.ipl.pt. \\ (2) APPsyCl - Applied Psychology Research Center Capabilities \& Inclusion, ISPA-Instituto Universitário, Lisboa, Portugal, \\ ORCID 0000-0002-6440-4739, clopes@ispa.pt. (3) Univ. Coimbra, Centro de Estudos Interdisciplinares do Século XX, \\ FLUC, Coimbra, Portugal, ORCID 0000-0002-7755-6168, mmb@fl.uc.pt. (4) UIDEF, Instituto de Educação, \\ Universidade de Lisboa, Portugal, ORCID 0000-0002-4902-2628, tsanches@fpie.ulisboa.pt
}

\section{Resumen}

Estudio preliminar sobre el impacto de la Ciencia Abierta en todo el ciclo científico, desde el inicio de la investigación hasta su publicación, buscando comprender, describir y explicar las percepciones de un grupo de investigadores sobre el ecosistema de la Ciencia Abierta. Se utilizó una metodología cualitativa, mediante entrevista semiestructurada. Los resultados identifican las dudas de los investigadores sobre el cumplimiento de las premisas de la ciencia abierta. La sistematización de sus ideas permite cuestionar si estarán preparados para estas nuevas experiencias en el campo de la ciencia y si tendrán las habilidades necesarias para garantizar su autonomía en la identificación de dónde publicar, cómo publicar, cómo gestionar los datos de investigación, cómo difundir los resultados de la investigación, cómo y por qué elegir los canales formales e informales de la ciencia, cómo utilizar las tecnologías en beneficio de su visibilidad y, finalmente, cómo asegurar la continuidad de su producción científica. El nuevo lenguaje utilizado también plantea muchas dificultades para los investigadores. Por ello, la creación de programas de formación para investigadores es un objetivo estratégico en los procesos de implementación de este paradigma de la ciencia.

Palabras clave: Ciencia abierta. Acceso abierto. Datos de investigación. Percepción de los investigadores. Entrevistas. Estudios cualitativo.

\section{Introdução}

O universo atual da ciência mudou, sobretudo após 2014. A União Europeia concebeu uma política de abertura da ciência à comunidade científica e à sociedade, com o objetivo de tornar acessível e reutilizável quer o conhecimento quer os dados de investigação, removendo barreiras regulatórias e impeditivas ao processo de inovação, simplificando os instrumentos de financiamento, derrubando os núcleos disciplinares para o estabelecimento efetivo da interdisciplinaridade

\begin{abstract}
Preliminary study on the impact of Open Science in the scientific cycle, from the beginning of the research to its publication, seeking to know, describe and explain the perceptions of a group of researchers regarding the Open Science ecosystem. A qualitative methodology was used, through a semi-structured interview. The results identify the researchers' doubts regarding the fulfilment of Open Science's premises. The systematization of their ideas allows us to question if they are prepared for these new experiences in the field of science and if they have the skills to ensure their autonomy to identify where to publish, how to publish, how to manage scientific data, how to disseminate research results, how and why to choose formal and informal channels of science, how to use technologies for the benefit of their visibility and, finally, how to ensure the perennity of their scientific production. Also, the new language used in Open Science raises many difficulties for researchers. Creating training programs for researchers is a strategic goal for the implementation process of this science paradigm.
\end{abstract}

Keywords: Open Science. Open Access. Research data. Researchers' perceptions. Interview. Qualitative study.

em ciência e cooperando estreitamente com os parceiros.

Esta política europeia foi concebida em torno dos três Os - Open Innovation, Open Science e Openness to the World (Labareda, 2019). A abertura à inovação (Open Innovation) implica um conjunto de políticas públicas e de investimentos visando projetos inovadores, envolvendo interlocutores diversificados e mobilizados no processo de inovação - investigadores, empresários, políticos e cidadãos -, num ambiente regulatório favorável à inovação e assente na evidência científica. A 
Ciência Aberta (Open Science) impulsiona novos mecanismos de difusão do conhecimento, em que as publicações académicas, nas quais se incluem as revistas científicas, devem ser facilmente acessíveis e os dados de investigação devem ser interoperáveis e reutilizáveis. Esta linha de atuação requer a prática do acesso aberto, bem como infraestruturas digitais fidedignas, mediante as quais os investigadores partilhem grandes quantidades de dados, mas também exige processos colaborativos e participativos dentro das equipas de investigação onde devem imperar elevados padrões de integridade. Finalmente, a abertura ao mundo (Openness to the World) significa a promoção da cooperação, traduzida em investigação colaborativa para solucionar desafios globais, como a escassez de água ou o coronavírus. Esta abordagem permite a expansão de projetos inovadores e permite que a sociedade considere a ciência como uma ferramenta eficaz de política externa para a promoção da paz.

O ecossistema da Ciência Aberta constitui, assim, um processo mais inclusivo e envolvendo muito mais atores. Investigadores de diferentes disciplinas trabalham agora juntos, quebrando tabus e limites na sua disciplina. O conhecimento e os dados de investigação circulam de modo mais fluido por intermédio de plataformas acessíveis e partilhadas. A cooperação é estabelecida através de uma rede de parcerias e de atividades regionais e globais, cujos objetivos são comuns, seja o terrorismo sejam as alterações climáticas.

$\mathrm{Na}$ atualidade, a aposta é feita na experimentação, na flexibilidade e na resposta à sociedade. Os investigadores precisam de liberdade para seguir a sua intuição e precisam de ser inovadores, sendo que os mais promissores projetos de investigação e inovação criaram a interseção de várias disciplinas. A Ciência Aberta assenta, deste modo, em princípios como o rigor, a responsabilidade, a reprodutibilidade, mas também a inclusão, a justiça, a equidade e a partilha na investigação (Projeto FOSTER, 2018), porque torna a ciência mais credível, confiável, eficiente e respondente aos desafios societais; dever-seá apostar na sua divulgação, promover os seus benefícios e apoiar os investigadores no cumprimento destas novas premissas.

A Ciência Aberta representa então uma nova abordagem para o processo científico, baseada no trabalho colaborativo e em novas formas de divulgar o conhecimento usando tecnologias digitais e novas ferramentas de igual modo colaborativas. Também expressa a transição de paradigma sobre como é desenvolvida a investigação, como colaboram os investigadores, como é partiIhado o conhecimento e como está organizada a ciência (Sanches, 2019). A Ciência Aberta representa, assim, a ligação do ambiente académico e de investigação a um público mais amplo, a transparência dos processos de investigação (recuperação, análise, publicação, crítica e reutilização dos dados) e o acesso aberto a dados e a publicações científicas (Leão, 2021), pelo que se deve ampliar a interlocução nos distintos pontos do ciclo desde a geração, partilha e disseminação do conhecimento (Borges \& Sanz Casado, 2021).

No atual contexto da Ciência Aberta, os princípios FAIR (findable, accessible, interoperable, and reusable) são diretrizes para os investigadores porque trabalham com a informação e com dados de investigação, não só na produção, como no tratamento, na curadoria ou na disseminação dos resultados (Projeto FOSTER, 2018). Para operacionalizar o ecossistema da Ciência Aberta, os princípios FAIR devem ser uma prática para a generalidade da comunidade científica, sendo muito importante entender a diversidade das disciplinas científicas, os obstáculos, mas também as lições aprendidas com os casos de sucesso.

Em síntese, a Ciência Aberta tem um importante impacto em todo o ciclo científico, desde o início da investigação até à sua publicação, mas também na forma como é organizado este ciclo. Questões como sistemas alternativos para o estabelecimento e consolidação da reputação científica, mudanças no modo como é avaliada a qualidade e o impacto da investigação, o uso crescente de blogues científicos, a revisão pelos pares aberta, o acesso aberto a dados e publicações, bem como o impacto económico da abertura dos dados de investigação, são algumas das premissas da Ciência Aberta (Projeto FOSTER, 2018; Lopes, Antunes \& Sanches, 2018; Borges \& Sanz Casado, 2021).

Perante o exposto e o atual contexto, o objetivo deste estudo preliminar (1) reside em conhecer, descrever e explicar as perceções de um conjunto de investigadores face ao ecossistema da Ciência Aberta.

\section{Métodos}

Foi usada uma metodologia qualitativa, através da realização de uma entrevista semiestruturada sobre as perceções de um grupo de investigadores portugueses sobre o ecossistema da Ciência Aberta.

Selecionou-se a análise qualitativa da entrevista de modo a facilitar o significado do que os entrevistados transmitem, mas também porque as entrevistas são particularmente úteis para divulgar a história existente por detrás das experiências dos entrevistados (Connaway \& Radford, 2016). Sendo uma forma mais pessoal de investigação, 
confirma-se a possibilidade de trabalhar diretamente com o entrevistado e de fazer perguntas de acompanhamento, sendo um processo geralmente facilitador para este.

A opção por uma entrevista semiestruturada traduziu-se na construção de um leque de questões, de modo a orientar o investigador no processo da entrevista. Mesmo incorporando alguns aspetos de conversação, constitui uma conversa guiada entre o investigador e o entrevistado; mantém alguma estrutura, mas também dá a capacidade de investigar o participante para a obtenção de detaIhes adicionais (Connaway \& Radford, 2016).

\subsection{Participantes}

Para este estudo foi usada uma amostra de conveniência, que procurou recolher as impressões de um conjunto diferenciado de investigadores, provenientes de áreas científicas diferentes, mas cujo exercício está associado ao campo da saúde: dois dos investigadores são de Saúde Ambiental, dois de Química, um de Nutrição, um de Medicina Nuclear/Imagem Médica e outro de Psicologia.

As características da amostra são as seguintes: a) quatro investigadores do sexo feminino e três do sexo masculino; b) a média de idades foi de 48 anos (mínimo de 39 anos e máximo de 54 anos); c) a média de anos no exercício da investigação foi de 15 anos, sendo que um dos entrevistados tem 30 anos de experiência; d) todos os investigadores são membros integrados em centros de investigação e só um dos entrevistados é um membro não integrado; e) todos representam centros de investigação que foram avaliados positivamente pela Fundação para a Ciência e Tecnologia (de Portugal).

\subsection{Entrevista semiestruturada}

As questões da entrevista semiestruturada procuram acompanhar as premissas do ecossistema da Ciência Aberta, a saber:

1. Tem conhecimento da existência de recomendações e políticas nacionais e europeias associadas à investigação científica? (e.g., Política Nacional de Ciência Aberta [FCT], Horizonte 2020 [Comissão Europeia]). Como obteve esse conhecimento? Conhece as implicações destes documentos no seu trabalho?

2. Quais são as suas maiores preocupações aquando da publicação de um manuscrito? Sabe que revista escolher e como escolher? Sabe o que são article processing charges (APC)? Sabe identificar as revistas de acesso aberto, as de via dourada, verde, bronze e híbridas? Sabe o que são e como identificar revistas predadoras?
3. Após a publicação do seu artigo, que destino dá aos seus dados? Associa-lhes metadados descritivos? Deposita-os num repositório de dados?

4. Regista digitalmente a sua propriedade científica? Identifica os seus trabalhos num perfil digital e permanente, como o Ciência ID, ORCID ou Researcher ID?

5. Como divulga o seu trabalho de investigação? Recorre às tecnologias (e.g., redes sociais académicas [quais?], redes sociais [quais?], repositório institucional ou temático)?

6. Como garante a preservação digital dos seus trabalhos? Deposita-os no repositório institucional, temático, num servidor de preprints, etc.?

\subsection{Procedimentos}

Foi realizado um pré-teste para afinação das questões. Os entrevistados foram informados do objetivo da entrevista, de que seria gravada e tiveram acesso às questões antes de iniciar. No final da entrevista procurou-se, de forma pedagógica, elucidar algumas das dúvidas patenteadas no decorrer da gravação. As entrevistas foram transcritas e identificadas pelas letras do alfabeto em maiúsculas ( $A, B, C, D, E, F$ e $G)$, de modo a facilitar a análise qualitativa. Na transcrição procurou-se dar alguma consistência à tónica discursiva. O texto das entrevistas foi posteriormente validado pelos investigadores.

As respostas às perguntas da entrevista semiestruturada foram objeto de uma análise qualitativa, através da técnica de análise de conteúdo, de acordo com os procedimentos de Neuendorf (2016).

\section{Resultados e Discussão}

Os resultados obtidos na análise de conteúdo às entrevistas semiestruturadas assinalaram respostas que se analisaram, questão a questão, sendo a discussão apresentada no mesmo alinhamento.

Q.1. Tem conhecimento da existência de recomendações e políticas nacionais e europeias associadas à investigação científica? (e.g., Política Nacional de Ciência Aberta [FCT], Horizonte 2020 [Comissão Europeia]). Como obteve esse conhecimento? Conhece as implicações destes documentos no seu trabalho?

Os entrevistados referem ter conhecimento destes normativos por intermédio dos centros de investigação que integram ou dos gabinetes de projeto das suas instituições. Um deles, porque 
integrou a comissão que preparou a avaliação do seu centro de investigação, teve de estudar estas recomendações. De um modo geral, creem que se trata de documentos referenciais que seguramente terão as suas implicações nos trabalhos de investigação, mas desconhecem todas as implicações - "Não sei se está relacionado com as publicações, as comissões de ética, a propriedade intelectual, o financiamento..." [entrevista F]; "Fico na dúvida se posso pôr no meu site um artigo tal como ele está, se tenho de pôr um preprint..." [entrevista G]. Um dos investigadores recorda-se de ler nestes documentos a recomendação de publicar os outputs da investigação em revistas de acesso aberto, num conceito de devolução à sociedade do investimento realizado.

\section{Q.2. Quais são as suas maiores preocupações} aquando da publicação de um manuscrito? Sabe que revista escolher e como escolher? Sabe o que são article processing charges (APC)? Sabe identificar as revistas de acesso aberto, as de via dourada, verde, bronze e híbridas? Sabe o que são e como identificar revistas predadoras?

Os investigadores reconhecem a necessidade e a urgência em publicar, não só para efeitos de dar a conhecer o seu envolvimento em projetos, como também para efeitos da sua avaliação de desempenho enquanto investigadores. Revelam, porém, dificuldades em identificar revistas verdes, bronze, douradas ou híbridas. Revelam também algumas reservas relativamente à fiabilidade de revistas de acesso aberto. O pior cenário parecem ser as revistas/editoras predadoras e as dificuldades assumidas para as identificar.

Aquando da submissão de um manuscrito para publicação, as preocupações dos investigadores começam pela aceitação, ou não, do trabalho para publicação. "Às vezes as revistas que nós escolhemos não são aquelas em que conseguimos publicar..." [entrevista B]. Depois gostariam que o artigo tenha visibilidade, que seja visto por outros e, porque não?, de contribuir com algum conhecimento na área. Um dos entrevistados [B], porque concluiu recentemente o doutoramento, refere que tem de começar a ter estas preocupações; até agora não as teve, essas questões passavam pelo orientador e este é que dava as melhores recomendações e indicava em que revistas submeter os artigos.

A qualidade da revista a selecionar parece ser um fator predominante. Um dos entrevistados [D] sabe normalmente onde publicar, como escolher (procura pela área científica, depois pelo fator de impacto e pelos quartis). Outro seleciona as revistas pela sua reputação na área científica onde mais publica (psicologia social); mas, se tiver de selecionar uma revista no âmbito da psicologia do desenvolvimento, já não sabe.

Ainda outro entrevistado confessa que receia não ter dinheiro para pagar taxas de publicação do manuscrito e para assegurar o acesso aberto; por isso, dentro do possível, analisa criticamente a qualidade do trabalho e tenta escolher a revista pelo seu fator de impacto e preferencialmente uma que não requeira taxas.

Refere ainda outro entrevistado que também prefere as revistas de acesso livre, ainda que uma boa parte do público-alvo da sua área de investigação se encontre afiliado em instituições que têm as revistas pagas porque as subscrevem. Também quando o financiamento da investigação não está previsto, os entrevistados procuram escolher revistas que não exijam taxas de publicação; acabam por não escolher o acesso aberto e depois os artigos não têm a mesma visibilidade que os outros [entrevista F].

Nenhum dos entrevistados soube identificar o que são APC. Genericamente sabem o que são revistas de acesso aberto, ponderam pagar taxas para publicar (especialmente se se tratar de uma rúbrica prevista no orçamento), um ou outro sabe o que são revistas de via dourada, mas desconhecem os conceitos de via verde, bronze e híbrida.

Parece ser uma realidade extensível a vários países e já retratada na literatura. Na Noruega, a maioria dos investigadores não está familiarizada com os diferentes métodos de publicação em acesso aberto (Moksness \& Olsen, 2020). Estes avaliam as revistas onde tencionam publicar de acordo com vários critérios, sendo que o fator qualidade é determinante. Mas a perceção deste fator qualidade envolve vários indicadores: prestígio, impacto, visibilidade, reputação e qualidade da revisão pelos pares.

A avaliação do fator de impacto de uma revista parece ser o indicador mais relevante, um selo de qualidade. Se as revistas de acesso aberto não tiverem fator de impacto, então, mesmo que as políticas nacionais e europeias recomendem a publicação em acesso aberto, prevalece a revista com fator de impacto - porque este fator é determinante na avaliação.

Investigadores e professores estão acostumados a publicar os seus trabalhos em revistas tradicionais (de acesso fechado), consideradas como canais de divulgação de prestígio. Entre as inúmeras razões que influenciam a escolha da revista, a progressão na carreira é das mais valorizadas. Os critérios utilizados na academia para avaliar o desempenho afetam fortemente as 
preferências dos seus investigadores (Chang, 2017). O que reforça a intenção dos investigadores em publicar em revistas de acesso aberto é a visibilidade; um artigo a que se acede, descarrega e divulga livremente tem o potencial de alcançar um público mais alargado do que aquele que tem de ser comprado (Swan, 2010; Projeto FOSTER, 2018). Mas, porque revelam ainda algum ceticismo relativamente à qualidade, ao prestígio e aos conteúdos disponibilizados em acesso aberto, dever-se-á promover quer a qualidade quer o impacto dos conteúdos em acesso aberto (Moksness \& Olsen, 2020), porque os investigadores precisam equilibrar a sua dupla função de investigadores e de académicos.

Os entrevistados reconhecem o conceito subjacente às revistas predadoras. Um dos entrevistados $[A]$ tenta sempre apurar o fator de impacto das revistas e outras informações e, em função disso, consegue de algum modo identificá-las. "Temos a caixa de correio invadida diariamente, no início eu achava o máximo, agora não acho piada nenhuma... todos os dias é uma revista nova - e publique, e quinze dias depois tem o artigo publicado..." [entrevista F].

Repararam que depois de fazer a revisão de alguns artigos começaram a receber emails a convidá-los a publicar. Desconfiam quando há muita publicidade associada ao nome de uma revista. Desconhecem, porém, que haja uma lista exaustiva com a identificação clara e inequívoca do que são revistas predadoras.

Procuram pesquisar - se não encontram dados no SciMAGO é porque é para ignorar -, podem concluir que não são revistas em que estejam interessados em publicar. Por curiosidade, até procuram em plataformas online listas de revistas predadoras para as manter identificadas e para poder marcar os emails que recebem como spam. Um dos entrevistados [G] refere questionar-se em algumas situações: tratar-se-á de uma revista nova à procura de potenciais autores? Mas genericamente as revistas predadoras assustam os entrevistados do presente estudo, não têm a certeza de as saber identificar e ignoram os emails que recebem.

Para a comunidade científica, o envio de emails em massa e não solicitados tem sido irritante. Os investigadores recebem muitos emails para uma call for papers, prometem uma revisão por pares rápida e revelam que as revistas são indexadas ou têm um elevado fator de impacto (Memon, 2018). Porém, estes convites por email têm sido uma maneira atraente para as revistas e editoras predadoras segmentarem as suas potenciais vítimas, geralmente investigadores júnior ou pouco experientes e oriundos de países em vias de desenvolvimento.

Neste contexto, as bibliotecas desempenham um importante papel pedagógico, alertando para novas práticas de persuasão usadas e para competências a adquirir para a identificação de revistas e editoras predadoras. Também os orientadores ou investigadores sénior estão mais familiarizados com este fenómeno fraudulento e podem ser de mais-valia para os mais jovens, dado que esta ameaça pode ser minimizada com mais informação e medidas reguladoras.

\section{Q.3. Após a publicação do seu artigo,}

que destino dá aos seus dados?

Associa-lhes metadados descritivos?

Deposita-os num repositório de dados?

A maioria dos entrevistados respondeu que, até ao momento, as revistas não exigiram a entrega dos dados de investigação ou o link do seu depósito num repositório de dados. Somente um dos entrevistados $[\mathrm{A}]$ se deparou com esta situação e, face ao seu desconhecimento e porque queria mesmo publicar naquela revista, solicitou ajuda ao seu centro de investigação. Mas, dependendo da área de investigação, podem ser encontrados vários cenários.

$\mathrm{Na}$ área da biomedicina, as comissões de ética assemelham-se a mediadores na utilização de dados (CIOMS, 2016). Os seus pareceres determinam que os dados se destinam explicitamente ao objeto de uma investigação, finalizada a qual devem ser abandonados. De um modo geral, os dados são habitualmente guardados de acordo com o que a Comissão de Ética determina: "agora manda-me deitar fora ao fim de algum tempo e tenho de [os] deitar... Os trabalhos mais antigos, como não tinha a obrigação de os deitar fora... nunca tive de deitar fora bases de dados (e tenho bases de dados antigas que, às vezes, até uso para fazer comparações com outras coisas)" [entrevista C]. Se lhe pedissem para depositar os dados num repositório de dados, esta investigadora teria de analisar se eticamente o poderia fazer; confessa que se sentiria desconfortável, porque os dados são dos doentes, os quais assinaram declarações de consentimento informado para participar e que, na maioria dos casos, não estão anonimizados - porque não é suposto: são dados confidenciais. Quando a entrega dos dados for um requisito inultrapassável, claramente esta investigadora terá de anonimizar os dados dos seus doentes.

Já um investigador da área da química respondeu que não dá um destino particular aos dados da investigação que realiza, normalmente ficam guardados no laboratório onde trabalha e 
também não têm metadados descritivos associados. Não teria problemas em entregar os seus dados se o editor de uma revista o solicitasse, até porque os seus dados são imagens, não recolhe dados de pessoas porque não trabalha com dados pessoais. Em química, a maioria dos dados são células, ficheiros e contagens de células. Em regra, o que é publicado é praticamente a totalidade do trabalho, dos resultados obtidos. Podem ser publicadas duas ou três imagens. O entrevistado [D] não teria problemas em publicar duzentas imagens, até porque as estatísticas estariam associadas a esse conjunto de informação (as duzentas). Não vê, por conseguinte, que seja problemática a divulgação dos seus dados e é seu propósito contribuir para um mega-repositório de imagens sobre a sua disciplina.

$\mathrm{Na}$ área da medicina nuclear e da imagem médica também se trabalha maioritariamente com imagens. Também se recorre à comissão de ética e o parecer emitido refere que os dados são usados exclusivamente para o objetivo do estudo, não podendo ser usados noutra investigação. Os investigadores até gostariam de retomar aqueles dados e tratá-los de outra forma, mas isso implica voltar à comissão de ética e aguardar por novo parecer. Face a um cronograma apertado, é provável que a investigação não seja retomada.

O investigador da área da psicologia [G] referiu que tem salvaguardado os seus dados no OSF (Open Science Framework, https://osf.io/) e pondera vir a realizar esse trabalho de uma forma retrospetiva, de modo a limpar as bases de dados que criou e a salvaguardar a informação primária.

Curiosamente, na amostra em estudo ficou demonstrado algum sentimento de propriedade dos dados de investigação: "guardo-os numa base de dados, numa cloud..." [entrevista C]; "guardo os meus dados... ficam comigo, ficam na minha base de dados mais pessoal" [entrevista F].

Q.4. Regista digitalmente a sua propriedade científica? Identifica os seus trabalhos num perfil digital e permanente, como o Ciência ID, ORCID ou Researcher ID?

Os investigadores têm a preocupação de garantir a propriedade e o registo digital dos seus trabaIhos. Maioritariamente usam o Ciência ID, o ORCID e o Researcher ID, sendo o último aquele que menos usam. Confessam que são recordados pelos próprios colegas de departamento para a necessidade de atualizar os seus perfis. Também as agências financiadoras exigem esta atualização para autorizar financiamentos e para garantir a continuidade dos projetos de investigação. Reconhecem a existência do conceito «sincronização», que gostariam que fosse mais operacional - a incompatibilidade entre plataformas parece manter-se ou, pelo menos, alguns itens não são completamente compatíveis. Um dos investigadores reforçou este enquadramento de propriedade legal, afirmando que na atualidade até para os livros que escreve ou os capítulos que o convidam a escrever tem a preocupação de verificar se está prevista a atribuição de ISBN.

A identificação da produção científica dos investigadores é feita através do seu nome - sem ambiguidades. Na medida em que a produtividade académica aumentou ao longo das últimas décadas é necessária a distinção clara e inequívoca das autorias, devido a nomes idênticos ou semeIhantes, mudanças de nome ao longo do tempo, uso de abreviaturas e iniciais (Reijnhoudt, Costas, Noyons, Borner \& Scharnhorst, 2014). O identificador de autor é um símbolo exclusivo para um autor, diferenciando o seu trabalho de todos os dos outros, independentemente de quaisquer semelhanças de nome, instituição ou disciplina (Francke, 2019). As ferramentas e os registos de autor que foram, entretanto, criados auxiliam os investigadores a identificar as suas publicações e a receber o reconhecimento pelos seus trabalhos.

De acordo com Tran e Lyon (2017), as áreas científicas manifestam algumas preferências. Genericamente, o ORCID e o Researcher ID têm uma utilização transversal em todas as disciplinas, exceto na matemática. O ORCID é muito utilizado nas ciências da saúde. O arXiv ID é preferencialmente usado por matemáticos, engenheiros e físicos, mas não por outras disciplinas. $\mathrm{O}$ Researcher ID é muito usado na física, mas não na matemática nem nas artes e humanidades. $\mathrm{O}$ Scopus ID é mais usado nas ciências da saúde. O Google Scholar ID tem mais popularidade nas ciências sociais, nas artes e humanidades, nas engenharias e nas ciências aplicadas.

Q.5. Como divulga o seu trabalho de investigação? Recorre às tecnologias (e.g., redes sociais académicas [quais?], redes sociais [quais?], repositório institucional ou temático)?

De um modo geral, os investigadores entrevistados recorrem ao repositório institucional e ao $\mathrm{Re}$ searchGate. São um pouco avessos às redes sociais - reservam-nas para assuntos pessoais, porque consideram uma futilidade o uso deste canal para a divulgação do seu trabalho científico. Mas admitem que é uma forma de todos ficarem a saber e de aumentar a possibilidade de citação. Reconhecem que o perfil de investigador 
na versão web do Mendeley é uma das formas de chegar a potenciais parceiros. Ao depositar a sua produção científica no ResearchGate, o principal objetivo do investigador é dar a conhecer o que publica à comunidade científica do ResearchGate, "que de todo não é igual àquela que encontramos no Facebook" [entrevista A]; os outros objetivos são identificar a investigação que os outros vão fazendo e estabelecer uma ligação com outros investigadores para o desenvolvimento de trabalho conjunto e colaborativo.

Revelam tranquilidade relativamente ao repositório institucional, porque "a Biblioteca é que trata disso tudo!" [entrevista C].

Um dos entrevistados assumiu que o preocupa o facto de a ciência circular dentro de um núcleo muito fechado, que é o dos próprios investigadores e académicos. Sugeriu que se deveriam promover sessões com jornalistas que comunicam ciência, porque devem existir outras formas de comunicar para chegar a outros públicos que são tão ou mais importantes do que aqueles a que convencionalmente os investigadores chegam [entrevista A].

A maioria dos estudos refere-se quase exclusivamente ao uso das redes sociais académicas por parte de investigadores e de professores do ensino superior. Porém, estes canais informais não distinguem categorias profissionais ou vínculos laborais, pelo que qualquer indivíduo ou qualquer estudante pode criar um perfil. Gostando ou não, a verdade é que as redes sociais académicas estão bem presentes na vida dos investigadores, para divulgar o seu trabalho, para conhecer outros investigadores, mas também para depositar uma versão integral de um texto indisponível em acesso aberto (Thelwall \& Kousha, 2015; Collins, Shiffman \& Rock, 2016; Nicholas, Herman \& Clark, 2016).

O ResearchGate e o Academia.edu são as redes sociais académicas mais usadas pelos investigadores. Os investigadores noruegueses parecem apreciar muito o ResearchGate, mas o Academia.edu é privilegiado pelos investigadores das humanidades (Mikki, Zygmuntowska, Gjesdal \& Ruwehy, 2015). Quase metade das pessoas no Academia.edu também tem uma conta no ResearchGate, mas inversamente o mesmo não acontece, o que corrobora o estudo de Manca (2018) que refere que o volume de informação do ResearchGate é claramente superior ao do Academia.edu, na medida em que os investigadores preferem um diálogo mais imediato com os seus pares sobre a utilização e a aprovação (ou não) dos seus trabalhos. Também Borrego (2017) destaca a experiência dos investigadores espanhóis ao privilegiar o uso do ResearchGate comparativamente aos repositórios institucionais.

Mas as redes sociais académicas acabam muitas vezes por ser comparadas, pouco favoravelmente, com os repositórios. Não existe nenhuma forma de equivalência entre estas duas opções. As redes sociais académicas são, do ponto de vista legal, entidades públicas com fins lucrativos, pelo que monitorizam quem, quando e de onde provêm autores e leitores. Não há qualquer garantia de que essas redes permaneçam perpetuamente. Ainda: são recursos que não podem ser considerados «abertos», porque é necessário um login+username (ou seja, outro perfil) para a obtenção dos textos integrais; assim, não é cumprido o mandato de acesso aberto de alguns financiadores. E, finalmente, podem apresentarse algumas questões legais associadas aos direitos de autor negociados com as editoras (Eva \& Wiebe, 2019).

Já os repositórios institucionais são o garante da produção científica e da preservação da memória académica e científica. Os bibliotecários são os primeiros a garantir metadados descritivos de qualidade; cabe aos investigadores atribuir igual mérito, submetendo os seus outputs preferencialmente num repositório.

Neste âmbito, as instituições de ensino superior podem assumir um papel mais ativo no processo de monitorização da sua designação junto das redes sociais. Também a implementação de uma política mandatória de depósito das publicações científicas associada à avaliação de desempenho dos seus professores e investigadores ajuda a monitorizar a produtividade individual, mas também institucional, com metadados descritivos validados pelas bibliotecas. Estas, por seu turno, ocupam uma posição privilegiada para o fornecimento de competências relacionadas com a divulgação e com a comunicação científica face aos múltiplos perfis disponíveis para os investigadores (Tran \& Lyon, 2017).

\section{Q.6. Como garante a preservação digital}

dos seus trabalhos? Deposita-os no repositório institucional, temático, num servidor de preprints, etc.?

A preservação digital é assegurada pelos repositórios institucionais, de acordo com os entrevistados. Reconhecem que as bibliotecas é que se encarregam de os recordar e de depositar a informação. Ainda assim, um dos entrevistados recorre também a um "Rdrive que lá tenho em casa..." [entrevista A] e outro "...no computador, esperando que nada lhe aconteça..." [entrevistas $B$ e G]. Outro investigador permite "o acesso a 
prints, dou acesso a tudo" [entrevista C], confiando que estas autorizações lhe garantam a perenidade do trabalho. Só um dos investigadores referiu que brevemente usará um servidor de preprints, o bioRxiv (https://www.biorxiv.org/), para colocar rapidamente um trabalho no mundo antes que alguém o faça antes [entrevista $D$ ].

Um dos entrevistados desempenhou, ao longo dos últimos dez anos, funções de gestão [entrevista E]. Dez anos em que abandonou a docência e a investigação para assegurar a gestão financeira da sua instituição, cargo para o qual foi nomeado. Agora que regressou ao ativo, sente que "perdeu o comboio". Não tem conhecimento de quaisquer recomendações e políticas nacionais e europeias associadas à investigação científica, nem as suas implicações no seu trabalho de investigação. Como não tem publicado nos últimos anos, desconhece o que são as vias douradas, verde e bronze das revistas científicas e também nunca ouviu falar de revistas predadoras. Ao longo dos últimos dez anos nunca teve preocupações com os dados de investigação, porque o seu trabalho de investigação ficou parado e também não publica há mais de dez anos. Desde que regressou à docência e à investigação criou um perfil ORCID onde registou os trabalhos que publicou há mais de dez anos e também os depositou no repositório institucional.

A entrevista $E$ é um bom exemplo das grandes transformações operadas nos últimos dez anos na comunidade científica, do conjunto de informação a que um júnior deve aceder para integrar uma equipa de investigadores e para se saber movimentar neste universo.

\section{Desenvolvimentos futuros}

Sistematizando as ideias veiculadas pelos investigadores entrevistados e associando-as aos estudos citados podem identificar-se algumas preocupações, a que se deve responder no futuro, designadamente:

- A instituição de recomendações e políticas nacionais e europeias, sobretudo porque enquadram e regulam a política de financiamento da investigação.

- A publicação em caráter de urgência, não só para efeitos de dar a conhecer o seu envolvimento em projetos, como também para efeitos da sua avaliação de desempenho enquanto investigadores. Os investigadores demonstraram grandes dificuldades em identificar revistas verdes, bronze, douradas ou híbridas, algumas reservas relativamente à fiabilidade das revistas de acesso aberto (ainda que Ihes reconheçam a visibilidade) e assumem grandes dificuldades em identificar revistas e editoras predadoras.

- A gestão de dados de investigação e os seus metadados descritivos deve ser um processo controlado pelos investigadores. Porém, para além dos receios de poderem perder o acesso e o controlo dos dados que consideram sua propriedade, estes assumem não o saber fazer. A biblioteca da sua organização ou o centro de investigação a que pertencem parecem ser as estruturas a que ponderam pedir ajuda.

- A clarificação, sem margem para dúvidas, da propriedade ou do registo digital da produção científica, usando perfis digitais que garantam identificadores permanentes e inequívocos, mas também perfis académicos disponibilizados pelos sites institucionais.

- A divulgação do trabalho de investigação, usando todos os recursos disponíveis. Porém, os investigadores não distinguem o valor e o impacto de canais formais e informais, destacando aqueles que lhes garantam contactos com outros investigadores. Neste entendimento, as redes sociais académicas não devem representar uma ameaça aos repositórios institucionais; devem ser uma ferramenta de marketing dos outputs científicos.

- A preservação digital do trabalho de investigação, assegurando a sua perenidade. Apesar de não identificarem claramente o valor dos repositórios institucionais é neles que pensam para o cumprimento deste desígnio.

- O esclarecimento de uma nova linguagem usada no campo da Ciência Aberta e as dificuldades evidenciadas pelos investigadores.

As ideias sistematizadas permitem questionar se os investigadores estarão preparados para estas novas experiências no campo da ciência e se possuirão as competências para garantir a sua autonomia na identificação de onde publicar, como publicar, como gerir os dados de investigação, como divulgar os resultados da investigação, como e porque escolher canais formais e informais da ciência, como usar as tecnologias em benefício da sua visibilidade e, finalmente, como assegurar a perenidade da sua produção científica.

\section{Conclusões}

Este estudo preliminar com uma abordagem qualitativa relata a experiência de um conjunto de investigadores portugueses no ecossistema da $\mathrm{Ci}$ ência Aberta. Revela que a nova linguagem usada no campo da ciência levanta muitas dúvidas junto dos investigadores, levando-os a demonstrar comportamentos diferenciados face à 
informação científica, mercê das suas (in)experiências, do que lhes é dito para fazerem, do que pensam ser o mais razoável e da interpretação, muitas vezes pessoal, que fazem das recomendações e das políticas nacionais e europeias.

A gestão dos dados de investigação, o uso das bases de dados criadas pelos investigadores e 0 recurso às comissões de ética são realidades enunciadas que colocam questões controversas, como o ficar coartada a possibilidade de se desenvolverem estudos comparativos com dados atuais e dados do passado.

Destaca-se, por fim, a divulgação do trabalho de investigação e o uso de canais formais e informais. Os investigadores demonstram compreender que uns e outros têm valor, utilidade e credibilidade, e que todos podem e devem ser usados, mas não podem ser avaliados no mesmo plano.

Este artigo, baseado numa metodologia qualitativa, requer estudos posteriores. Apesar de trazer um significativo aporte de experiências diferenciadas entre si, importa ampliar o número de investigadores inquiridos.

No futuro, e no alinhamento das conclusões, equaciona-se a realização de dois estudos complementares, para aprofundamento, designadamente: a) a construção de um instrumento mais objetivo, que envolva uma representatividade maior de investigadores e uma análise metodológica quantitativa; e b) a sistematização dos eixos de atuação dos investigadores no ecossistema da Ciência Aberta, de modo a delinear um conjunto de estratégias formativas.

\section{Notas}

(1) Programa de Doutoramento em Ciência da Informação (Universidade de Coimbra, Portugal).

\section{Referências}

Borges, Maria Manuel; Sanz Casado, Elías (Eds.). (2021). Sob a lente da Ciência Aberta: olhares de Portugal, Espanha e Brasil. Coimbra: Imprensa da Universidade de Coimbra, 2021.

Borrego, Angel. (2017). Institutional repositories versus ResearchGate: the depositing habits of Spanish researchers. // Learned Publishing. 30 (2017) 185-192.

Chang, Yu-Wei. (2017). Comparative study of characteristics of authors between open access and non-open access journals in library and information science. // Library \& Information Science Research. 39:1 (2017) 8-15.

CIOMS (2016). International ethical guidelines for health-related research involving humans. Geneva: Council for International Organizations of Medical Sciences, 2016.

Collins, Kimberley; Shiffman, David; Rock, Jenny (2016). How are scientists using social media in the workplace? // PLoS One. 11:10 (2016), e0162680.

Connaway, Lynn; Radford, Marie L. (2016). Research methods in library and information science. $6^{\text {th }}$ ed. Libraries Unlimited.
Eva, Nicole; Wiebe, Tara (2019). Whose research is it anyway? Academic social networks versus institutional repositories. // Journal of Librarianship and Scholarly Communication. 7 (2019) eP2243.

Francke, Helena (2019). The academic web profile as a genre of 'self-making'. // Online Information Review. $43: 5$ (2019) 760-774.

Labareda, João (2019). Open Europe: policies, reforms and achievements in EU science and innovation 2014-2019. Luxembourg: Publications Office of the European Union, 2019.

Leão, Delfim F. (2021). O momentum da Ciência Aberta. // Borges, Maria Manuel; Sanz Casado, Elías (Eds.). Sob a lente da Ciência Aberta: olhares de Portugal, Espanha e Brasil. Coimbra: Imprensa da Universidade de Coimbra, 2021.

Lopes, Carlos; Antunes, Maria Luz; Sanches, Tatiana (2018). Contributos da literacia da informação para a Ciência Aberta. // Ibersid. 12:1 (2018) 59-67.

Manca, Stefania (2018). ResearchGate and Academia.edu as networked socio-technical systems for scholarly communication: a literature review. // Research in Learning Technology. 26 (2018)

Memon, Aamir (2018). Predatory journals spamming for publications: what should researchers do? // Science and Engineering Ethics. 24:5 (2018) 1617-1639.

Mikki, Susanne; Zygmuntowska, Marta; Gjesdal, Øyvind; Al Ruwehy, Hemed (2015). Digital presence of Norwegian scholars on academic network sites: where and who are they? // PLoS One. 10:11 (2015) e0142709.

Moksness, Lars; Olsen, Svein (2020). Perceived quality and self-identity in scholarly publishing. // Journal of the Association for Information Science and Technology. 72:3 (2020) 338-348.

Neuendorf, Kimberley (2016). The content analysis guidebook. Los Angeles: Sage, 2016.

Nicholas, David; Herman, Eti; Clark, David (2016). Scholarly reputation building: how does ResearchGate fare? // International Journal of Knowledge Content Development \& Technology. 6:2 (2016) 67-92.

Projeto FOSTER. (2018). Manual de formação em Ciência Aberta. Bruxelas: FOSTER, 2018.

Reijnhoudt, Linda; Costas, Rodrigo; Noyons, Ed; Börner, Katy; Scharnhorst, Andrea (2014). Seed + expand: a general methodology for detecting publication oeuvres of individual researchers. // Scientometrics. 101:2 (2014) 1403-1417.

Sanches, Tatiana (2019). Changing roles for research and information skills development: librarians as teachers, researchers as learners. // Kurbanoğlu, Serap; Špiranec, Sonja; Ünal, Yurdagül; Boustany, Joumana; Huotari, Maija; Grassian, Esther; et al. (Eds.). Information literacy in everyday life: ECIL 2018, communications in computer and information science. Cham: Springer, 2019. 462-471.

Swan, Alma (2010). The open access citation advantage: studies and results to date. University of Southampton, 2010. Doctoral thesis. https://eprints.soton.ac.uk/268516 (2020-01-20)

Thelwall, Mike; Kousha, Kayvan (2015). ResearchGate: disseminating, communicating and measuring scholarship? // Journal of the American Society for Information Science and Technology. 66:5 (2015) 876-889.

Tran, Clara; Lyon, Jennifer (2017). Faculty use of author identifiers and researcher networking tools. // College and Research Libraries. 78:2 (2017) 171-182.

Enviado: 2021-04-01. Segunda versión: 2021-07-21. Aceptado: 2021-11-13. 
